\title{
Economical and efficient technique for a static localized maximum sun lux determination
}

\author{
Ahmed H. Ali ${ }^{1}$, Adel S. Nada ${ }^{2}$, Ahmed S. Shalaby \\ ${ }^{1}$ Department of Telecommunication Engineering, Egyptian Russian University, Egypt \\ ${ }^{2,3}$ Department of Electrical Engineering, Al-Azhar University, Egypt
}

\begin{tabular}{l} 
Article Info \\
\hline Article history: \\
Received Oct 28, 2018 \\
Revised Jan 26, 2019 \\
Accepted Mar 3, 2019 \\
\hline
\end{tabular}

\section{Keywords:}

Arduino Uno

LDRs

Micro SD memory card

Real time counter (RTC)

\begin{abstract}
Solar energy is one of the most promising renewable sources that is currently being used worldwide to contribute for meeting rising demands. In this paper solar irradiance measurement will experimentally carried out in two different regions in Egypt; Cairo and Luxor cities. This paper proposes a simple solar lux measurement using a light dependent resistor (LDR) with an arduino kit. This technique is based on two approaches which are coarse and fine maximum sun lux determination. This is based on the predetermined $26^{\circ}$ vertical slop of the LDR. Coarse tuning determines one of the reach sun lux quarter $\left(90^{\circ}\right)$ of horizontal quad. The fine tuning allocates the optimized $10^{\circ}$ in which; the maximum sun lux can be obtained. The optimal values of sun lux were found between the $\left(90^{\circ}-180^{\circ}\right)$ quarter. This study confirms that the narrow ten degrees $\left(95^{\circ}-105^{\circ}\right)$ are the optimized static sun lux extraction for the two site field measurements. This novel technique can be used for locating the angle of best installations for the solar cell at which maximum solar energy can be extracted.
\end{abstract}

Copyright (C) 2019 Institute of Advanced Engineering and Science. All rights reserved.

\section{Corresponding Author:}

Ahmed H. Ali,

Department of Telecommunication Engineering,

Egyptian Russian University, Egypt,

Badr City, Cairo-Suez Road, Postal Code 11829.

Email: ahmed_hamdy0064@yahoo.com

\section{INTRODUCTION}

Measurement of the solar irradiation intensity in a specified position is the key to study the optimal design and to predict the performance and efficiency of photovoltaic (PV) systems [1,2]. The performance of a PV system, module or array depends on many factors; one of which is the solar irradiance that the could solar panels receive during the day (peak sun-hours) [3, 4].

The total solar radiation potential will be key parameter for designing and predicting the performance of solar energy equipment and solar energy potential $[5,6]$. It has been verified that the higher altitude greater the total solar radiation under the clear and intermediate sky conditions. Under the overcast days the solar radiation is very low in comparison with sunny days $[7,8]$. The solar radiant energy on the earth's surface is a requirement not only in the studies of climate change, environmental pollution but also in agriculture, hydrology, food industry and promotion of overall solar energy technology programs [9-11]. Measuring of the solar irradiance at different positions is one of the most important tools to catch the maximum solar radiation. Siti Amely Jumaat and Mohamad Hilmi Othman (MATEC Web of Conferences, 2018) measured the solar irradiance using LDR at three modules; sunrise position, upward position and sunset position [12].

The high cost of the design of solar irradiance devices, such as the pyranometer [13], and the irradiance meter, is the significant problem [14]. These devices can measure irradiance with high accuracy 
and cover a wide spectral range. These devices such as lux meter $[15,16]$ can therefore be expensive and also sometimes need special installation prior to the measurement $[17,18]$.

This paper develops a lower cost, easy to use platform to determine a localized maximum sun lux. This solution looks a competitive for the most alternatives. Two different regions in Egypt (Cairo and Luxor) of different solar profiles as shown [19] in Figure 1 are selected for verifying the proposed system validity. The choice of the angles is made for collecting the most concentrated solar irradiation varying with time [2022]. The choice of areas is due to their different weather and sun shines [23].

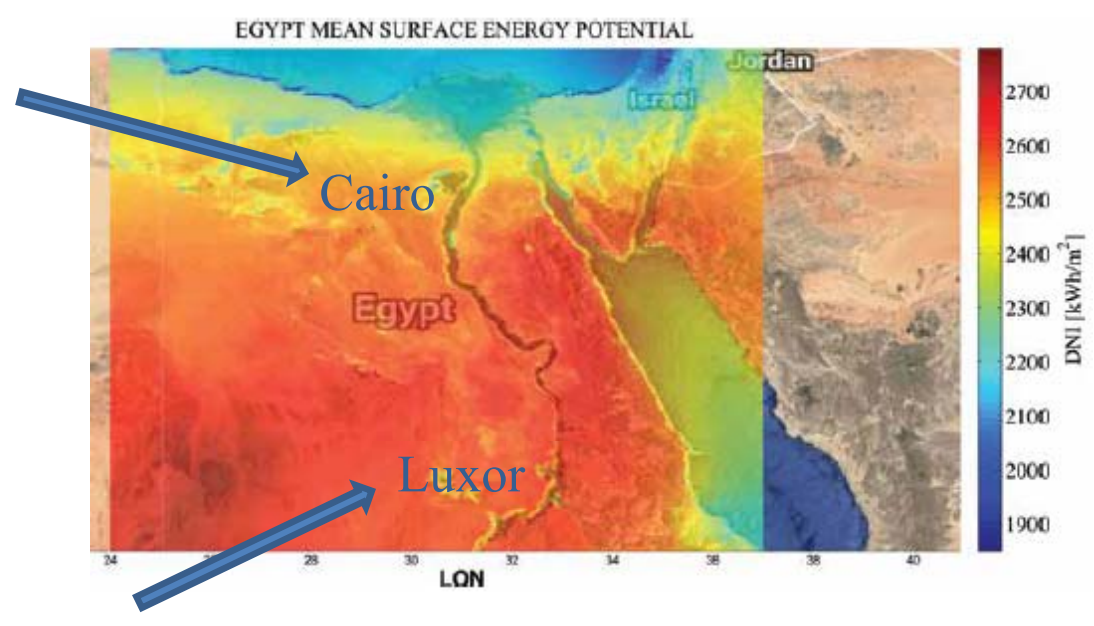

Figure 1. The solar atlas of Egypt

\section{OPERATIONAL PROCEDURE}

The whole system is activated where the arduino is connected to group of LDR for two steps of the peak lux coarse and fine as shown in Figure 2. The proposed system configured of two main modules as followings:

\subsection{Coarse lux determination}

During this procedure that called coarse determination, a LDR has installed at each arm of the quad directions (north, south, east and west).

\subsection{Fine lux determination}

Additional steps are including the LDR installation at $\left(90^{\circ}, 100^{\circ}, 110^{\circ}\right.$ and $\left.120^{\circ}\right)$ of second quarter $\left(90^{\circ}-180^{\circ}\right)$ for determining the most appropriate sun lux presence.

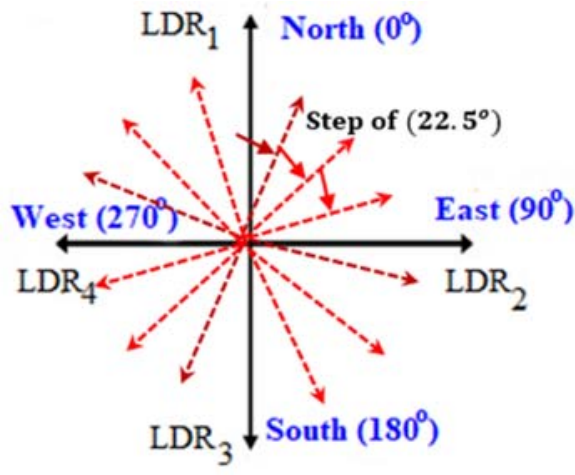

(a) Coarse lux determination

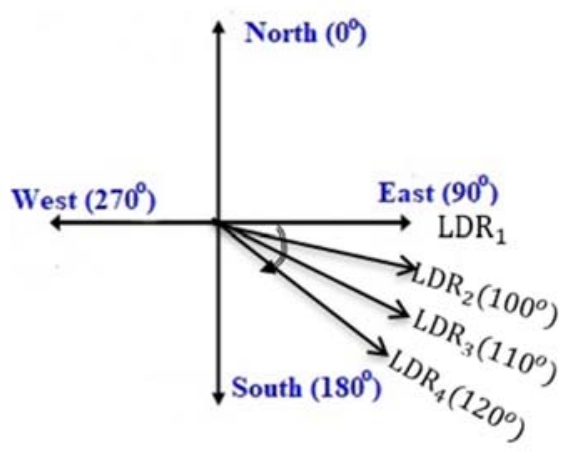

(a) Fine lux determination

Figure 2. Stepped sun lux tracer 


\section{THE SYSTEM PLATFORM}

In this work, the main controller which is the arduino receives analog input from LDRs and it converts the input into digital signal by using analog-to-digital (A/D) converter. Then the controller sends the measured lux values to SD memory card (storage). The block diagram of the experimental work is shown in Figure 3.

This project is divided into two stages namely, hardware and software development. In hardware development, four light dependent resistors (LDRs) were utilized to capture the maximum light source from the sun, RTC to retain time of reading and memory for data storage. In the software part, the code was constructed by using $\mathrm{C}++$ programming language and was targeted to the arduino uno controller.

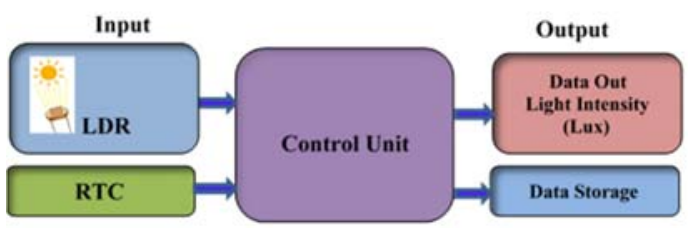

Figure 3. Block diagram of overall system

\subsection{System hardware}

This work hardware platform configured of three main parts as follows:

\subsubsection{Light dependent resistor (LDR)}

Light dependent resistor (LDR) sensor: A light sensor is used to sense devices illumination level of the sun light. A photoresistor is a sensor which electrical resistance is altered depending on the light intensity falling on it. In spite of the PD sun sensor availability [24, 25], the resistance of the LDR is inversely proportional to the light intensity at higher sensitivity degree.

\subsubsection{Arduino board}

The arduino uno is microcontroller board ecosystem that consists of a processor platform on the ATmega328. It has 14 digital input and output pins: 6 pins used PWM outputs and 6 pins is analog input such as the clock speed is $16 \mathrm{MHz}$, the ceramic resonator, the USB connection, the power jack, the ICSP header and the reset button.

\subsubsection{Real time clock (RTC) module}

A real-time clock (RTC) is a computer clock (most often in the form of an integrated circuit) that keeps track of the current time. This should not be confused with hardware clocks which are only signals that govern digital electronics, and do not count time in human units. The RTC module keeps accurate time for years using a tiny coin-cell, and is very simple to connect to the Arduino board. The module uses the Arduino analog pins $\mathrm{A}_{4}$ and $\mathrm{A}_{5}$ for "I2C" serial communications with the sketch. No other pins on the arduino are used by the module other than power and GND, so they are all available for connection to other devices in your projects. A driver library allows a program to easily set or read the time and date.

The arduino requires a power supply $12 \mathrm{~V}$ adapter. The controller works with $6 \mathrm{~V}$ de power supply while sensors, RTC and SD memory work with $5 \mathrm{~V}$ DC power voltage divider or DC chopper can therefore, be used.

\subsection{The system software}

This system uses the arduino IDE on the windows platform to develop the application of auto sunlight measurements. The arduino integrated development environment (IDE) is used to write and upload the computer code to the physical board. Arduino IDE is a cross platform application developed using Java. It is available for Windows, Linux and Mac operating systems. The graphical data representation is implemented on Microsoft excel.

\section{THE EXPERIMENTAL WORK}

A photo diode accompanied with $9 \mathrm{~V}$ relay driven by BC547BP transistor is used as a day/system operation starter. The soft operation of the system is developed according to the flow chart of Figure 4 . The source codes were targeted to arduino uno board to be compiled and uploaded. The four LDRs were

Economical and efficient technique for a static localized maximum sun lux determination (Ahmed H. Ali) 
connected to arduino analog pins $\mathrm{A}_{0}$ to $\mathrm{A}_{3}$ to act as the input for the system. The built-in analog-to-digital converter (ADC) transforms the analog value of LDR into digital pulse width modulation (PWM). Each LDR was connected with fixed resistance and then connected to the arduino to read sun lux. The readings were taken every 10 minutes by RTC module to know it's time readings which connected with the arduino and the readings were stored in SD memory card. Prototype was placed on a building roof because for much more sunlight detection. The experiment carried out start of July up to October, 2018.

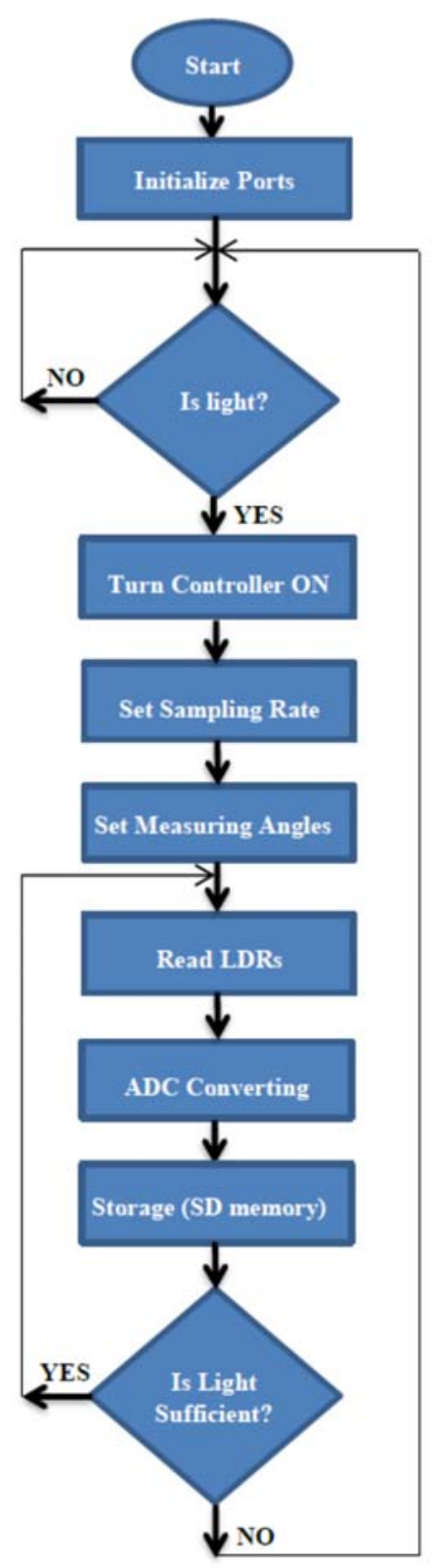

Figure 4. System procedure flow chart

The work is designed first on the famous drawing program CorelDraw we have used in drawing the solar tracking system circuit and drawing the base of the control circuit. Second, we performed the drawings on the machine $\mathrm{CNC} \mathrm{Co} 2$ laser cutting and engraving machine to implement the proposed system. Figures 5 and 6 shows the schematic diagram that illustrates the measurements of the solar irradiations. 


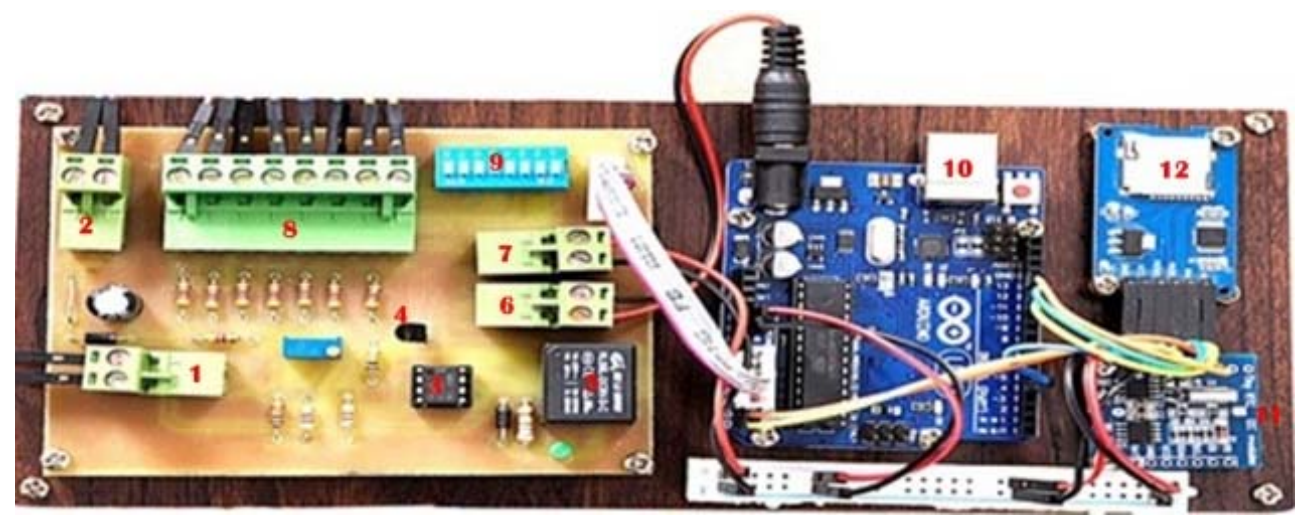

Figure 5. The experimental proposed control system, 1) LDR starter, 2) 9V from adaptor, 3) Operational amplifier, 4) Transistor BC547BP, 5) Relay 9V, 6) 9V to arduino, 7) 5V from arduino, 8) 7 jumpers from LDRs, 9) Switch from 7 jumpers from LDRs to analog pins of arduino, 10) Arduino Uno, 11) RTC module,

(12) SD memory card

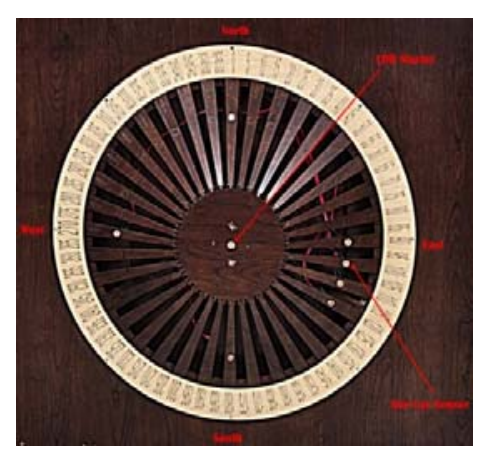

Figure 6. Arrangement of sensor for sun lux measurements

The LDR was first mounted at the northern zero and the lux was recorded. The same procedure was repeated for different angles.

\section{RESULTS AND ANALYSIS}

The proposed sun lux tracer (SLT) configured of a fixed orthogonal quad LDRs that are allocated at the quad direction (north, south, east and west). During the coarse sun lux determination, the results showed that the quarter $\left(90^{\circ}-180^{\circ}\right)$ has the peak lux detection. This is accomplished at Luxor and Cairo as shown in Figures 7 and 8, respectively. These curves will indicate the sun lux rising and decaying during daylight hours.

The peak value of the sun lux is differing from Cairo to Luxor cities, Figures 7 and 8, respectively that it can due to the difference of the sky clearance of the two cities. The accurate limited sector that can grantee the greatest radiated energy of the sun is allocated by installing the LDR at the angles $90^{\circ}, 100^{\circ}, 110^{\circ}$ and $120^{\circ}$. The measured results of Cairo and Luxor cities are depicted as shown in Figures 9 and 10 respectively. The closes results of the Luxor may be due to the lower sky fogs and dust.

It is observed from the experimental results of Figures 9 and 10 that the angle $100^{\circ}$ has the maximum sun lux. For significantly identification of this optimized angle; the lux was repeatedly measured along different days to verify the obtained results. Figures 11 and 12 show that the recommended measurements of $100^{\circ}$ angle have almost peak values for these different days. This shows that the sun lux is independent on the week days. This can explain why no need for MPPT mechanical solutions. This of course will grant reliable and long-life time PV system utilization. Figure 11 displays the measurement results similarity and stability due to the sky clearance as depicted in Figure 9.

The results confirmed that the Egyptian sun light offers higher than 1500 lux for around eight hours in case of clean sky. The sun lux of the other national cities is much better than Cairo state which attributed

Economical and efficient technique for a static localized maximum sun lux determination (Ahmed H. Ali) 
to the factories spread around the Cairo state. On the other hand, Luxor city has been selected as another location of the national cities. The inter dependence of the life time as well as the additional cost of the mechanical solution for tracking system are sufficient enough to search any other technique. The results assure that the mechanical maximum power point track (MPPT) can waste power much more than that can be added.

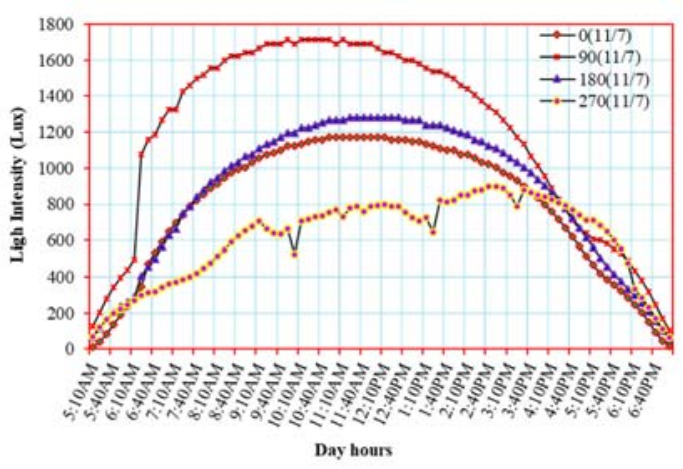

Figure 7. Readings in Luxor city with coarse selecting angles

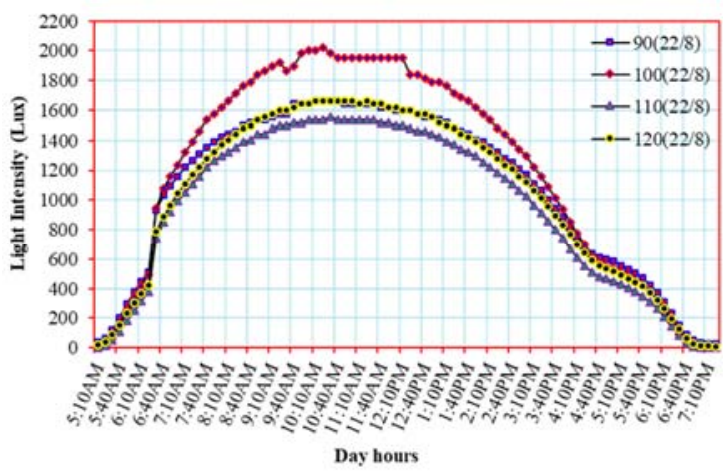

Figure 9. Luxor measurements at fine sectors (angles)

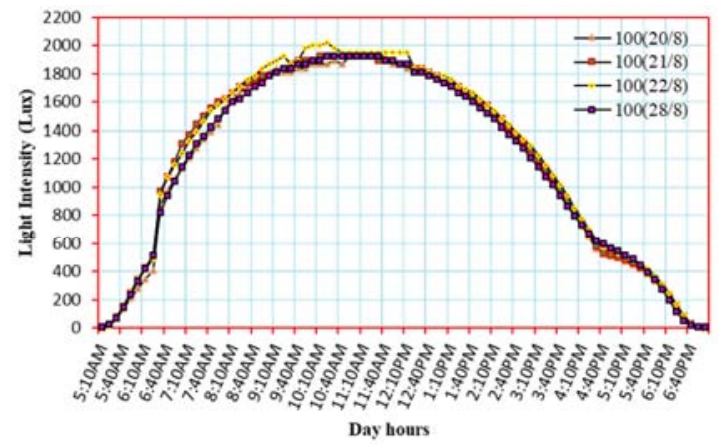

Figure 11. Readings in Luxor city of $100^{\circ}$ angle

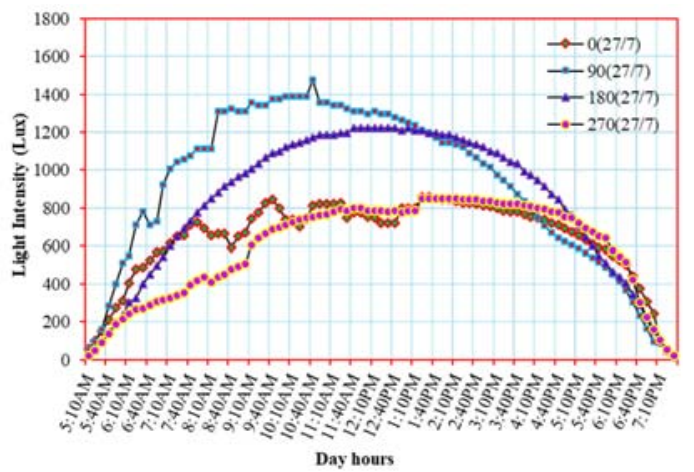

Figure 8. Readings in Cairo with coarse selecting angles

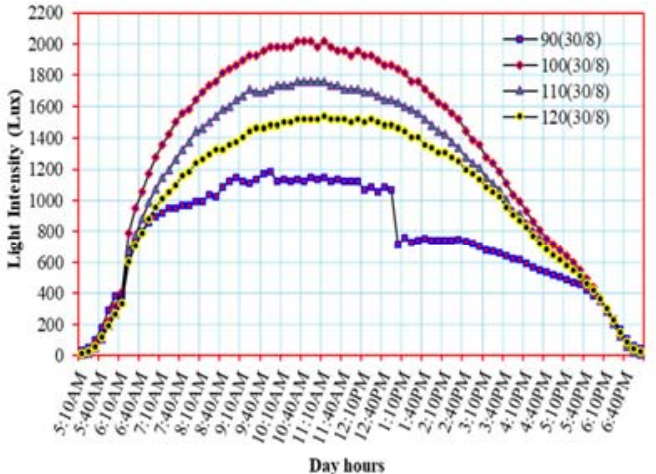

Figure 10. Readings in Cairo at fine sectors (angles)

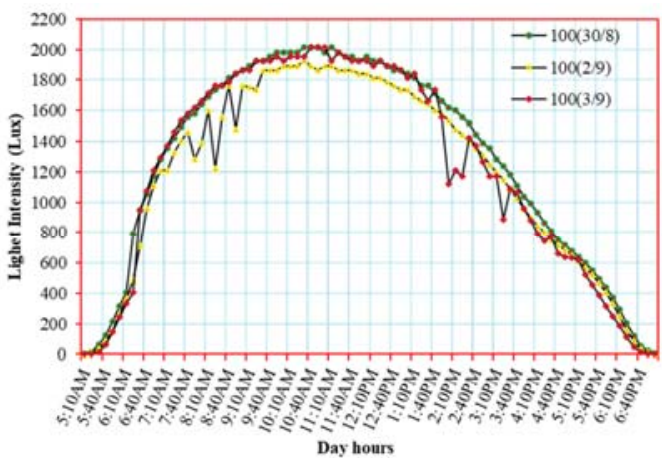

Figure12. Readings in Cairo city of $100^{\circ}$ angle 


\section{CONCLUSIONS}

Low cost, easy to use and efficient technique for a static localized maximum sun lux estimator has been proposed and implemented. It provides in a short time (day to view days) an accurate angle of maximum sun lux. This system can be considered a competitive alternative to the mechanical maximum power point track (MPPT) systems. The light intensity has been measured using the LDR sensor connected to an arduino based system. The obtained measurements at many days have almost maximum values at $100^{\circ}$ angle. A resultant cost reduction and long-life time of the photovoltaic (PV) system utilization have therefore achieved. This work will be continued up to filling the whole year sun lux profile

\section{ACKNOWLEDGEMENTS}

The authors are pleased to thanks Associate Prof. Dr. El-Sayed Soliman Ahmed Said for his contribution and sharing during this work.

\section{REFERENCES}

[1] H. Al-Taani and S. Arabasi, "Solar Irradiance Measurements Using Smart Devices: A Cost-Effective Technique for Estimation of Solar Irradiance for Sustainable Energy Systems," Sustainability, vol. 10(2), 508, pp. 1-11, 2018

[2] C. K. Pandey and A. K. Katiyar, "Solar Radiation: Models and Measurement Techniques," Journal of Energy, vol. 2013, pp. 1-8, 2013

[3] M. Bagheritabar, H. Bagheitabar, M. M. R. Kashani, and N. S. Khodashenas, "Photovoltaic Systems with Rotational Panels to Harvest Natural and Artificial Light for Electrical Production," $5^{\text {th }}$ International Conference on Electrical and Electronics Engineering, pp. 211-214, 2018.

[4] A. A. Abdulrazzaq and A. H. Ali, "Efficiency Performances of Two MPPT Algorithms for PV System With Different Solar Panels Irradiances," International Journal of Power Electronics and Drive System (IJPEDS), vol. 9, no. 4, pp. 1755-1764, 2018.

[5] E. Kabir, P. Kumar, S. Kumar, A. A. Adelodun, and Ki-H. Kime, "Solar Energy: Potential and Future Prospects," Renewable and Sustainable Energy Reviews, vol. 82, no. 1, pp. 894-900, 2018.

[6] P. D. A. Aziz, S. S. A. Wahid, Y. Z. Arief, and N. A. Aziz, "Evaluation of Solar Energy Potential in Malaysia," Trends Bioinform, vol. 9, no. 2, pp. 35-43, 2016.

[7] D. O. Akinyele and R. K. Rayudu, "Comprehensive Techno-Economic and Environmental Impact Study of a Localised Photovoltaic Power System (PPS) for Off-Grid Communities," Energy Conversion and Management, vol. 124, pp. 266-279, 2016.

[8] S. N. Khine and Z. Tun, "Sensor Analysis and Application of Arduino based Temperature and Light Intensity Control for Smart Home System," International Journal of Scientific and Research Publications, vol. 8, no. 6, pp. 89-94, 2018.

[9] U. A. S. K. Edirisinghe, "Study to Evaluate The Effectiveness of Lighting System by Using LED Technology in Commercial Buildings," M.Sc. Thesis, University of Vocational Technology, 2012.

[10] M. Oki and H. Shiina, "Preliminary Study on an Estimation Method for Annual Solar Irradiance at Various Geographical Altitudes," 8 ${ }^{\text {th }}$ International IBPSA Conference, Eindhoven, Netherlands, pp. 11-14, 2003.

[11] K. Muthukumar and T. S. Anandhi, "Real Time Implementation of Variable Step Size Based P\&O MPPT for PV Systems Based on dSPACE," International Journal of Power Electronics and Drive System (IJPEDS), vol. 7, no. 3, pp. 915-925, 2016.

[12] S. A. Jumaat and M. H. Othman, "Solar Energy Measurement Using Arduino," MATEC Web of Conferences, vol. 150 , pp. 1- 6, 2018

[13] S. M. Raihan, R. Muhida, M. H. Ullah, and L. Sulastri, "Design of a radio telemetry solar radiation sensor using solar cell," American journal of scientific research, vol. 10, pp. 78-86, 2010.

[14] K. R. Ajao, R. M. Ambali, and M. O. Mahmoud, "Determination of The Optimal Tilt Angle for Solar Photovoltaic Panel in Ilorin, Nigeria," Journal of Engineering Science and Technology Review, vol. 6, no. 1, pp. 87-90, 2013.

[15] A. H. Ismail, M. S. M. Azmi, M. A. Hashim, M. N. Ayob, M. S. M. Hashim, and Hassrizal H.B., "Development of a Webcam Based Lux Meter," IEEE Symposium on Computers and Informatics, pp. 70-74, 2013.

[16] S. Sumriddetchkajorn and A. Somboonkaew," Low-Cost Cell Phone-Based Digital Lux Meter," The International Society for Optical Engineering, vol. 7853, pp. 1-6, 2010.

[17] K. N. Poudyal, B. K. Bhattarai, B. K. Sapkota, B. Kjeldstad, and N. R. Karki, "Estimation of Global Solar Radiation using Pyranometer and NILU-UV Irradiance Meter at Pokhara Valley in Nepal," Journal of the Institute of Engineering, vol. 9, no. 1, pp. 69-78, 2013.

[18] M. Elyaqouti, S. Hakim, S. Farhat, L. Bouhouch, and A. Ihlal, "Implementation in Arduino of MPPT Using Variable Step Size P\&O Algorithm in PV Installations," International Journal of Power Electronics and Drive System (IJPEDS), vol. 8, no. 1, pp. 434-443, 2017.

[19] H. El-Askary, P. Kosmopoulos, and S. Kazadzis, "The Solar Atlas of Egypt," Ministry Of Electricity and Renewable Energy, Egypt, pp. 1-277, 2018.

[20] M. Mirzaei and M. Z. Mohiabadi, "Comparative Analysis of Energy Yield of Different Tracking Modes of PV Systems in Semiarid Climate Conditions: The Case of Iran," Renewable Energy, vol. 119, pp. 400-409, 2018. 
[21] S. Bazyari, R. Keypour, S. Farhangi, A. Ghaedi, and K. Bazyari, "A Study on the Effects of Solar Tracking Systems on the Performance of Photovoltaic Power Plants," Journal of Power and Energy Engineering, vol. 2, no. 4, pp. 718-728, 2014.

[22] A. Abdulmula, K. Sopian, L. C. Haw, and A. Fazlizan, "Performance evaluation of standalone double axis solar tracking system with maximum light detection MLD for telecommunication towers in Malaysia," International Journal of Power Electronics and Drive System (IJPEDS), vol. 10, no. 1, pp. 444-453, 2019.

[23] N. Kannan and D. Vakeesan, "Solar Energy for Future World: - A review," Renewable and Sustainable Energy Reviews, vol. 62, pp. 1092-1105, 2016.

[24] M. Sumathi, R. Ranjan, R. K. Singh, and P. Kumar, "Performance Analysis of Sun sensors for Satellite systems," International Conference on Advanced Electronic Systems, pp. 10-14, 2013.

[25] R. Saleem and S. Lee, " Accurate and Cost-Effective Micro Sun Sensor Based on CMOS Black Sun Effect," Sensors, vol. 19, no. 3, pp. 1-17, 2019.

Int J Pow Elec \& Dri Syst, Vol. 10, No. 2, June 2019: 777 - 784 